\title{
Recent Advances in Dental Hard Tissue Remineralization: A Review of Literature
}

\author{
Mando K Arifa ${ }^{1}$, Rena Ephraim², Thiruman Rajamani ${ }^{3}$
}

\begin{abstract}
The dental caries is not simply a continuous and unidirectional process of the demineralization of the mineral phase, but a cyclic event with periods of demineralizations and remineralisation. The remineralization process is a natural repair mechanism to restore the minerals again, in ionic forms, to the hydroxyapatite (HAP) crystal lattice. It occurs under near-neutral physiological pH conditions whereby calcium and phosphate mineral ions are redeposited within the caries lesion from saliva and plaque fluid resulting in the formation of newer HAP crystals, which are larger and more resistant to acid dissolution. Numerous types of remineralizing agents and remineralizing techniques have been researched and many of them are being used clinically, with significantly predictable positive results. The recent researches on remineralization are based on biomimetic remineralization materials, having the capability to create apatite crystals within the completely demineralized collagen fibers.
\end{abstract} Keywords: Nanoparticles, Polydopamine, Recent advances, Remineralizaion. International Journal of Clinical Pediatric Dentistry (2019): 10.5005/jp-journals-10005-1603

\section{INTRODUCTION}

Dental caries is a pandemic disease affecting the teeth characterized by demineralization and cavitation, eventually leading to discomfort and pain, causing limitations in function and compromised facial aesthetics. ${ }^{1}$

Most of the children acquire the bacteria (predominantly Streptococcus mutans) from their mothers or caregivers by salivary contact during the emergence of primary teeth between the ages 6 and 30 months of life and is termed as a discrete window of infectivity. ${ }^{2,3}$ Caries is not simply a continuous and unidirectional process of the demineralization of the mineral phase, but a cyclic event with periods of demineralizations and remineralization. ${ }^{4}$ When the demineralization process predominates, it leads to cavitation.

The demineralization process involves loss of minerals at the advancing front of the lesion, at a depth below the enamel surface, with the transport of acid ions from the plaque to the advancing front and mineral ions from the advancing front toward the plaque. ${ }^{5}$ The remineralization process is a natural repair mechanism to restore the minerals again, in ionic forms, to the hydroxyapatite (HAP) crystal lattice. ${ }^{6}$ It occurs under near-neutral physiological $\mathrm{pH}$ conditions whereby calcium and phosphate mineral ions are redeposited within the caries lesion from saliva and plaque fluid resulting in the formation of newer HAP crystals, which are larger and more resistant to acid dissolution. ${ }^{7}$

The chemical basis of the demineralization-remineralization process is similar for enamel, dentin, and root cementum. However, the different structures and relative quantity of mineral and organic tissue content of each of these materials cause significant differences in the nature and progress of the carious lesion. ${ }^{8}$

\section{BACKGROUND}

In the 1980s, it was well established that fluoride can control caries lesion causing remineralization of demineralized enamel. Later, Fazzi et al. in 1997 demonstrated that the fluoride gets permanently bound to the enamel crystal to form fluorapatite crystals. ${ }^{9}$ In 2001, Duggal et al. have proved that the reduced

\begin{abstract}
${ }^{1-3}$ Department of Pediatric and Preventive Dentistry, Mahe Institute of Dental Sciences and Hospital, Mahe, Puducherry, India

Corresponding Author: Mando K Arifa, Department of Pediatric and Preventive Dentistry, Mahe Institute of Dental Sciences, Mahe, Puducherry, India, Phone:+91 9447974585, e-mail: arifashameem303@ gmail.com

How to cite this article: Arifa MK, Ephraim R, et al. Recent Advances in Dental Hard Tissue Remineralization: A Review of Literature. Int J Clin Pediatr Dent 2019;12(2):139-144.

Source of support: Nil

Conflict of interest: None
\end{abstract}

acid solubility of fluorapatite may be attributed to the lower carbonate content in it. ${ }^{10}$ High amounts of fluoride in dentifrices and systemic fluorides have shown signs of toxicity which later led to the development of nontoxic fluoride alternatives as effective remineralizing agents.

The use of casein phosphopeptides (CPPs) as an anticariogenic and anticalculus was first described by Reynolds in 1993 and then amorphous calcium phosphate (ACP)-filled methacrylate composites 1996. ${ }^{11}$ In 1999, Enamelon toothpaste based on ACP technology was commercially developed by $\mathrm{Dr}$ Tung. ${ }^{12}$ Then, in 2003, sugar-free chewing gums and mouth rinses containing CPP-ACP were in use, which has shown to remineralize the subsurface enamel lesions. ${ }^{13}$

Sodium calcium phosphosilicate (bioactive glass) ceramic material which can provide calcium, sodium, and phosphate ions to form a hydroxyl carbonate apatite (HCA) was introduced as a remineralizing agent as it can attach to the tooth surface and release ions for remineralization. A toothpaste named "NovaMin" was introduced by Dr LenLitkowsky and Dr Gary Hack based on this formulation. ${ }^{6}$ The recent researches on remineralization are on biomimetic remineralization materials which were initially put forward by Moradian in 2001. ${ }^{14}$

Numerous types of remineralizing agents and remineralizing techniques have been researched and many of them are being used clinically, with significantly predictable positive results. 
Requirements of an ideal remineralization material are as follows:

- Diffuses into the subsurface or delivers calcium and phosphate into the subsurface

- Does not deliver an excess of calcium

- Does not favor calculus formation

- Works at an acidic pH

- Works in xerostomic patients

- Boosts the remineralizing properties of saliva ${ }^{7}$

\section{Classification}

Remineralizing agents have been broadly classified into the following:

- Fluorides

- Nonfluoride remineralizing agents

- Alpha tricalcium phosphate (TCP) and beta TCP ( $\beta$-TCP)

- Amorphous calcium phosphate

- CPP-ACP

- Sodium calcium phosphosilicate (bioactive glass)

- Xylitol

- Dicalcium phosphate dehydrate (DCPD)

- Nanoparticles for remineralization

- Calcium fluoride nanoparticles

- Calcium phosphate-based nanomaterials.

- NanoHAP particles

- ACP nanoparticles

- Nanobioactive glass materials

- Polydopamine

- PA

- Oligopeptides

- Theobromine

- Arginine

- Self-assembling peptides

- Electric field-induced remineralization

\section{Fluoride}

Soi et al. have mentioned four mechanisms of action of fluoride. ${ }^{15}$ Fluoride inhibits demineralization as the fluorapatite crystals, formed by reaction with enamel apatite crystals, are more resistant to acid attack compared to HAP crystals. Second, fluoride enhances remineralization as it speeds up the growth of the new fluorapatite crystals by bringing calcium and phosphate ions together. Third, it inhibits the activity of acid producing carious bacteria, by interfering with the production of phosphoenol pyruvate (PEP) which is a key intermediate of the glycolytic pathway in bacteria. And also, the $\mathrm{F}^{-}$retains on dental hard tissue, the oral mucosa and in the dental plaque to decrease demineralization and enhance remineralization. ${ }^{15}$

\section{Fluoride-containing Dentifrices}

Toothpastes can contain fluoride in various chemical forms mainly as sodium fluoride ( $\mathrm{NaF})$, sodium monofluorophosphate $\left(\mathrm{Na}_{2} \mathrm{FPO}_{3}\right)$, amine fluoride $\left(\mathrm{C}_{27} \mathrm{H}_{60} \mathrm{~F}_{2} \mathrm{~N}_{2} \mathrm{O}_{3}\right)$, stannous fluoride $\left(\mathrm{SnF}_{2}\right)$, or combinations of these. Sodium fluoride directly provides free fluoride. Sodium monofluorophosphate is the fluoride of choice when calcium containing abrasives are used. The fluoride released is absorbed to the mineral surface, as a $\mathrm{CaF}_{2}$ or a $\mathrm{CaF}_{2}$-like deposit, in free or bound form. Stannous fluoride provides fluoride and stannous ions where the latter act as an antimicrobial agent. ${ }^{16}$

Fowler et al. found that toothpaste formulations containing $1426 \mathrm{ppm} F$ as sodium fluoride or 1400 ppm F as amine fluoride gave a significant protection of enamel from erosive acid challenges in vitro compared to $0 \mathrm{ppm} F$ placebo toothpaste. ${ }^{17}$ In fluoride pastes with zinc and amino acids, the basic amino acid inhibits the formation of insoluble zinc fluoride. The available zinc aids in protecting against erosion, reducing bacterial colonization and biofilm development, and provides enhanced shine to the teeth. According to Pradubboon et al., $0.05 \mathrm{NaF}$ mouth rinse combined with twice-daily regular use of fluoride toothpaste, when used twicedaily, effectively enhances the remineralization of incipient caries. ${ }^{18}$

Another mode of fluoride delivery is the light-activated fluoride (LAF) treatment method, where the fluoride topical treatment is immediately followed by the application of intense monochromatic light sources, such as light emitting diodes (LED) or halogen curing lights (470-500 nm) and blue argon ion laser (488 nm). An in vivo study by Mehta et al. using a single application of a lightcurable fluoride varnish (Clinpro T) has proven its effectiveness in preventing demineralization. ${ }^{19}$

\section{Calcium Phosphate Compounds}

Calcium phosphate is the principal form of calcium found in bovine milk and blood. As the major components of hydroxyapatite (HA) crystals, concentrations of calcium and phosphate in saliva and plaque play a key role in influencing the tooth demineralization and remineralization processes. ${ }^{20}$ At equal degrees of supersaturation, an optimal rate of enamel remineralization can be obtained with a calcium/phosphate ratio of 1.6. In the plaque fluid, the $\mathrm{Ca} / \mathrm{P}$ ratio is approximately $0.3 .^{20}$ So additional calcium supply may augment enamel remineralization.

\section{$\beta-T C P$}

Studies have shown that the combination of TCP with fluoride can provide greater enamel remineralization and build more acid-resistant mineral relative to fluoride alone. ${ }^{20}$ When it is used in toothpaste formulations, a protective barrier is created around the calcium, allowing it to coexist with the fluoride ions. During toothbrushing, TCP comes into contact with saliva, causing the barrier to dissolve and releasing calcium, phosphate, and fluoride. ${ }^{6}$

\section{Functionalized TCP}

Functionalized TCP is a low-dose calcium phosphate system that is incorporated into a single-phase aqueous or non-aqueous topical fluoride formulation. It provides a barrier that prevents premature TCP-fluoride interactions and also facilitates a targeted delivery of TCP when applied to the teeth. ${ }^{20}$

\section{Dicalcium Phosphate Dihydrate (DCPD)}

DCPD is a precursor for apatite that readily turns into fluorapatite in the presence of fluoride. ${ }^{21}$ Researches have shown that inclusion of DCPD in a dentifrice increases the levels of free calcium ions in the plaque fluid, and these remain elevated for up to 12 hours after brushing, when compared to conventional silica dentifrices. ${ }^{6,22}$

\section{ACP}

ACP is the initial solid phase that precipitates from a highly supersaturated calcium phosphate solution and can convert readily to stable crystalline phases such as octacalcium phosphate or apatitic products. ${ }^{22}$ It plays as a precursor to bioapatite and as 
a transient phase in biomineralization. ${ }^{11}$ The conversion of ACP to apatite at physiological $\mathrm{pH}$ has been described as followings: initially, there is dissolution of $A C P$, then reprecipitation of a transient OCP solid phase through nucleation growth, and, finally, hydrolysis of the transient OCP phase into the thermodynamically more stable apatite by a topotactic reaction. ${ }^{21,23}$

\section{ACP-filled Composites}

A biologically active restorative material containing ACP as a filler encapsulated in a polymer binder was introduced by Skrtic, which can stimulate the repair of tooth structure by releasing significant amounts of calcium and phosphate ions. It releases calcium and phosphate ions into saliva and deposit into tooth structures as an apatitic mineral, which is similar to the HAP found naturally in teeth and bone. ${ }^{24}$ Enamelon $^{\mathrm{TM}}$ is a toothpaste, consisting of unstabilized calcium and phosphate salts with sodium fluoride. It has been shown to be superior to conventional fluoride dentifrice in preventing root surface caries in radiotherapy patients. ${ }^{6}$

\section{CPP-ACP}

This protein nanotechnology was developed by Eric Reynolds and co-workers, where CPP is a milk-derived protein, and it can stabilize clusters of ACP into CPP-ACP complexes, because at neutral $\mathrm{pH}$, the "acidic motif" in CPP is a highly charged region which can bind to minerals such as $\mathrm{Ca}^{2+}, \mathrm{Zn}^{2+}, \mathrm{Fe}^{2+}, \mathrm{Mn}^{2+}$, and $\mathrm{Se}^{2+}$. CPP-ACP is a two-phase system which when mixed together reacts to form the ACP material that precipitates onto the tooth structure and elevates calcium levels in the plaque fluid. GC Tooth Mousse Plus ${ }^{\mathrm{TM}}$ and MI Paste Plus ${ }^{\mathrm{TM}}$ are formulations of CPP-ACP with incorporated fluoride to a level of $900 \mathrm{ppm}$, where the fluorides give additive effects in reducing caries experience. ${ }^{21}$ It is available as toothpastes, chewing gum, lozenges, and mouth rinses. According to Prestes et al., an in situ study has shown that chewing gum containing CPP-ACP can significantly enhance mineral precipitation of initial bovine enamel lesions, contributing remarkably in its microhardness recovery. ${ }^{25}$

Reynolds et al. have reported that the addition of 2\% CPPACP to the $450 \mathrm{ppm}$ fluoride mouth rinse significantly increases the incorporation of fluoride into plaque. Oliveira et al. also have demonstrated a greater protective effect against demineralization on smoother surfaces if CPP-ACP was combined with fluoride than without fluoride. ${ }^{26}$ Chicken egg shell powder (CESP) solution with higher calcium content and calcium sucrose phosphate (ENAFIX) have also shown its greater remineralization potential of enamel in in vitro studies. ${ }^{27,28}$

\section{Bioactive Materials}

A bioactive material is defined as a material that stimulates a beneficial response from the body, particularly bonding to host bone tissue and to the formation of a calcium phosphate layer on a material surface. ${ }^{29}$ Bioglass (BG) is a class of bioactive material which is composed of calcium, sodium, phosphate, and silicate. They are reactive when exposed to body fluids and deposit calcium phosphate on the surface of the particles. ${ }^{30}$ In vitro and in vivo studies have shown that BG particles can be deposited onto dentine surfaces and subsequently occlude the dentinal tubules by inducing the formation of carbonated HAP-like materials. ${ }^{31}$

\section{S5 BG}

45S5 BG originally developed by Hench et al. ${ }^{32}$ consists of $45 \%$ $\mathrm{SiO}_{2}, 24.5 \% \mathrm{Na}_{2} \mathrm{O}, 24.5 \% \mathrm{CaO}$, and $6 \% \mathrm{P}_{2} \mathrm{O}_{5}$ in weight. It is a highly biocompatible material possessing remarkable osteoconductivity, osteoinductivity, and controllable biodegradability. ${ }^{33}$ With the decreasing particle size, adhesive capacity onto the enamel surface increased, but the mechanical properties will be decreased gradually. ${ }^{34}$

NovaMin ${ }^{\mathrm{TM}}$ is a bioactive glass containing $45 \% \mathrm{SiO}_{2}, 24.5 \% \mathrm{Na}_{2} \mathrm{O}$, $24.5 \% \mathrm{CaO}$, and $6 \% \mathrm{P}_{2} \mathrm{O}_{5}$. NovaMin particles would bind to the exposed dentin surface to form a protective HCA layer as well as physically fill the open tubules. When particles of the NovaMin material are exposed to an aqueous environment such as water or saliva, there is an immediate release of sodium ions, which increases the local $\mathrm{pH}$ leading to precipitation of the ions to form the HCA layer. ${ }^{35}$

\section{Nanomaterials}

Nanoparticles have better ion release profiles than microparticles. ${ }^{8}$ Since it is difficult to directly use nanomaterials to remineralize teeth in the oral environment, these materials are often added to restorative materials as inorganic fillers, such as resin composites to release calcium, phosphate, and fluoride ions for remineralization of dental hard tissues. ${ }^{8}$

\section{Calcium Fluoride Nanoparticles}

$\mathrm{Xu} \mathrm{HHK}$ et al. have shown that the addition of nanoCaF $\mathrm{F}_{2}$ increases the cumulative fluoride release compared to the fluoride release in traditional glass ionomer cements because the $\mathrm{CaF}_{2}$ nanoparticle (nano- $\mathrm{CaF}_{2}$ ) has a 20-fold higher surface area compared with traditional glass ionomer cements. ${ }^{8}$

\section{Calcium Phosphate-based Nanomaterials}

It includes nanoparticles of HAP, TCP, and ACP as sources to release calcium/phosphate ions and increase the supersaturation of HAP in carious lesions. ${ }^{8}$

\section{$\beta-\operatorname{TCP}\left(\mathrm{Ca}_{3}\left(\mathrm{PO}_{4}\right)_{2}\right)$}

$\beta$-TCP can be functionalized with organic and/or inorganic materials to form the so-called functionalized $\beta-\mathrm{TCP}(\mathrm{f} \beta-\mathrm{TCP})$.

\section{NanoHAP Particles}

Nano-sized HAP (n-HAP) is similar to the apatite crystal of tooth enamel in morphology and crystal structure. So it can be substituted for the natural mineral constituent of enamel for repair biomimetically. ${ }^{8}$ Li et al. have indicated that n-HAP particles with a size of $20 \mathrm{~nm}$ fits well with the dimensions of the nanodefects on the enamel surface caused by acidic erosion and the nanoparticles can strongly attach to the demineralized enamel surface and inhibit further acid attack. According to Meghna Amin et al., commercially available nanoHAP pastes are effective in reducing the dentinal hypersensitivity if used for 6 months as a desensitizing agent. ${ }^{36}$ Amaechi et al. have shown that nanoHAP-containing and NovaMincontaining toothpastes are equally effective in occluding dentin tubules. ${ }^{37}$ Even though the results from experiments are promising, the stability and the mechanical properties of the n-HAP are inferior, and its clinical application is limited because it takes long time (from several hours to days) for the formation of the mineral. ${ }^{8}$

\section{ACP Nanoparticles}

They are small spheroidal particles with a dimension in the nanoscale (40-100 nm). ACP nanoparticles, as a source of calcium and phosphate ions, have been added to composite resins, ionomer cements, and adhesives. A study using in situ caries models of humans have revealed that nanoACP-containing nanocomposites prevented demineralization at the restoration-enamel margins, producing lesser enamel mineral loss compared with the control composite. ${ }^{8}$ In vitro studies by Xu Zhang have confirmed that the 
remineralizing rate of Pchitosan-ACP complexes' treatments were significantly higher than that of fluoride treatment. ${ }^{8}$

\section{Nanobioactive Glass Materials}

Sheng et al. have found that nanoBG particles could promote mineral formation on dentin surfaces and they were shown to make dentin more acid resistant. ${ }^{38}$

\section{Xylitol}

Xylitol is a tooth friendly nonfermantable sugar alcohol which has been shown to have noncariogenic as well as cariostatic effects. ${ }^{39}$ It exerts the anticariogenic effects by the inactivation of $S$. mutans and inhibition of plaque's ability to produce acids and polysaccharides. When consumed as mints or gum, it will stimulate an increased flow of alkaline and mineral-rich saliva from small salivary glands in the palate. Increased salivary flow results in increased buffering capacity against acids and high mineral content will provide the minerals to remineralize the damaged areas of enamel. ${ }^{39}$

There are contradictory reports about the added effectiveness of xylitol, especially when combined with fluoride from the researchers. Milburn et al. have shown that fluoride varnish, containing xylitol-coated calcium and phosphate, had the greatest initial fluoride release in the first four hours, exceeding 10 times than that of other varnishes such as Enamel Pro ${ }^{\oplus}$, Duraphat ${ }^{\oplus}$, or Vanish. ${ }^{40}$ However, Brown et al. could not find any added clinically relevant preventive effect of xylitol on caries in adults with adequate fluoride exposure. ${ }^{41}$

\section{Biomimetic Remineralization of the Dentin and Enamel}

Most of these studies on remineralization were based on the epitaxial deposition of calcium and phosphate ions over existing apatite seed crystallites. ${ }^{42}$ According to this concept, remineralization does not occur in locations where seed crystallites are absent particularly in completely demineralized dentin due to the unavailability of seed crystallites in those regions. At the same time, biomimetic remineralization aims in attempting to backfill the demineralized dentin collagen with liquid-like ACP nanoprecursor particles that are stabilized by biomimetic analogs of noncollagenous proteins. ${ }^{42}$ In this so-called nonclassical particlebased crystallization concept, calcium and phosphate ions are sequestered by biomimetic analogs of noncollagenous proteins involved in hard tissue mineralization into nanoparticles. These prenucleation clusters $(\approx 1 \mathrm{~nm}$ in diameter) eventually aggregate into larger (10-50 nm in diameter) liquid-like ACP nanoparticles. It then penetrates into the intrafibrillar water compartments of a collagen fibril and undergoes self-assembly and crystallographic alignment to form a metastable crystalline phase. These crystals fuse finally into single apatite crystallites within the zone between the collagen molecules. ${ }^{42}$

\section{Polydopamines}

The oxidative polymerization of dopamine in aqueous solutions spontaneously forms polydopamine, mimicking DOPA, which exhibits a strong adhesive property to various substrates under wet conditions. ${ }^{43}$ In demineralized dentin, the collagen fibers when coated with polydopamine, remineralization was promoted, which shows that polydopamine binding to collagen fiber act as a new nucleation site that will be favorable for HA crystal growth.

\section{PA}

PA is a bioflavonoid, containing benzene-pyran-phenolic acid molecular nucleus. Grape seed extract (GSE) contains PA, ${ }^{44}$ which can form visually insoluble HA complexes when mixed with a remineralizing solution at $\mathrm{pH}$ 7.4. Cheng-fang Tan et al. noticed a concentration-dependent increase in the microhardness when caries-like acid-etched demineralized dentine was treated with proanthocyanidins-rich GSE. Moreover, Epasinghe et al. have proved in vitro the synergistic effect of PA when combined with CPP amorphous calcium fluoride phosphate (CPP-ACFP) on remineralization of artificial root caries in which they noticed an enhanced mineral gain and increased the hardness of artificial root caries. ${ }^{45}$

\section{Self-assembling Peptide}

Recent developments in research have revealed the role of treatment with peptide where it proved a combined effect of increased mineral gain and inhibition of mineral loss from the tooth. The $\beta$-sheet-forming peptides, P114, that self-assemble themselves to form three-dimensional scaffolds under defined environmental conditions have been shown to nucleate HAP. The anionic groups of the $\mathrm{P} 114$ side chains attract $\mathrm{Ca}^{++}$ions, inducing the precipitation of HAP in situ. ${ }^{46}$

\section{Electric Field-induced Remineralization}

Wu have introduced this technique to remineralize the completely demineralized dentin collagen matrix and also to shorten the mineralization time, which it achieved in the absence of both calcium phosphates and their analogs with the help of electrophoresis. ${ }^{47}$

\section{Polyamide}

Poly(amidoamine) (PAMAM) dendrimers are known as artificial proteins which mimic the self-assembly behavior of amelogenins to form a similar structure in vitro and is used as an organic template to control the synthesis of HAP crystals. ${ }^{48}$ The researches of Chen et al. on the effect of PAMAM dendrimers modified with the carboxylic acid groups $(\mathrm{COOH})$ on the crystallization of HAP on etched enamel surface have proved that polyamide act as an organic template on the demineralized enamel surface to induce the formation of HAP crystals with the same structure, orientation, and mineral phase of the intact enamel in relatively short time. ${ }^{48}$

\section{Theobromine}

Theobromine is a member of the xanthine family, seen in cocoa (240 mg/cup) and chocolate (1.89\%), and has shown to enhance crystalline growth of the enamel. ${ }^{49}$ In a comparative evaluation of the remineralizing potential of theobromine and sodium fluoride dentifrice by Amaechi et al., a significantly higher mineral gain was observed with theobromine and fluoride toothpaste relative to artificial saliva. ${ }^{49}$ Grace Syafira et al. have shown an increased enamel microhardness after treatment with theobromine on the enamel surface. ${ }^{50}$ Meanwhile, Abdillah Imron Nasution has noticed that the increase in hardness of the enamel surface by fluoride application is higher than the theobromine..$^{51}$

\section{Arginine Bicarbonate}

Arginine bicarbonate is an amino acid with particles of calcium carbonate, which is capable of adhering to the mineral surface. When the calcium carbonate dissolves, the released calcium is 
available to remineralize the mineral while the release of carbonate may give a slight local $\mathrm{pH}$ rise. ${ }^{23}$ The studies on the demineralized bovine enamel blocks by Yamashita et al. with arginine and fluoride formulations have shown that when used in combination with fluoride, arginine significantly increased fluoride uptake compared with fluoride alone, and lesions treated with arginine containing toothpaste also showed superior fluoride uptake compared with those treated with conventional fluoride toothpaste. ${ }^{52}$

\section{Conclusion}

In recent years, the focus of restorative dentistry has been directed toward a conservative approach, out of which remineralization procedures are the most preferred and optimal way of regeneration of lost tooth structure. The preventive approach of identification, conservation, and non-restorative treatment of incipient caries saves both dental manpower and expense and suffering for the patient.

In the present review, an attempt has been made to review the various remineralization materials and technologies currently being employed to remineralize enamel and dentin. Initially, fluoride formulations were only the material relied on, which responded by rebuilding the HAP crystals, supplying the necessary ions, which were partially lost from the lattice network. Later the researches could successfully introduce newer biomimetic remineralization products having the capability to create apatite crystals within completely demineralized collagen fibers. It is expected that further experiments in this field would definitely bring out better products and technologies for clinical application with optimal responses and results.

\section{References}

1. Edelstein B. The dental caries pandemic and disparities problem. BMC Oral Health 2006;6(1):S1-S2. DOI: 10.1186/1472-6831-6-S1-S2.

2. Berkowitz RJ, Turner J, et al. Maternal salivary levels of Streptococcus mutans and primary oral infection of infants. Arch Oral Biol 1981;26:147-149. DOI: 10.1016/0003-9969(81)90086-8.

3. Caufield PQ, Cutter GR, et al. Initial acquisition of mutans streptococci by infants: evidence for a discrete window of infectivity. J Dent Res 1993;72:37-45. DOI: 10.1177/00220345930720010501.

4. Carounanidy U, Sathyanarayanan R. Dental caries: a complete changeover (part I). J Conserv Dent 2009;12(2):46-54. DOI: 10.4103/0972-0707.55617.

5. Robinson C, Shore RC, etal. The chemistry of enamel caries. Crit Rev Oral Biol Med 2000;11(4):481-495. DOI: 10.1177/10454411000110040601.

6. Hemagaran G. Remineralisation of the tooth structure-the future of dentistry. Int J PharmTech Res 2014;6(2):487-493.

7. Naveena Preethi P, Nagarathana C, et al. Remineralising agent-then and now - an update. Remineralising agent-then and now - an update. Dentistry 2014;4(9):1-5.

8. Zhang $X$, Deng $X$, et al. Remineralising Nanomaterials for Minimally Invasive Dentistry. Chapter Nanotechnology in Endodontics: Current and Potential Clinical Applications. Switzerland: Springer International Publishing; 2015. pp. 173-193.

9. Amaechi BT, Loveren Monogr CV. Fluorides and non-fluoride remineralisation systems. Monogr Oral Sci 2013;23:15-26. DOI: 10.1159/000350458.

10. Peter S. Essentials of public health dentistry, 5th edn; 2013.

11. Zhao J, Liu Y, et al. Amorphous calcium phosphate and its application in dentistry chemistry. Cent J 2011;5(40):2-7.

12. Tung MS, Eichmiller FC. Dental applications of amorphous calcium phosphates. J Clin Dent 1999;10:1-6.

13. Reynolds EC. Retention in plaque and remineralisation of enamel lesions by-various forms of calcium in a mouthrinse or sugarfree chewing gum. J Dent Res March 2003;82(3):206-211. DOI: 10.1177/154405910308200311.
14. Moradian-Oldak J. Amelogenins: assembly, processing and control of crystal morphology. Matrix Biol 2001;20:293-305. DOI: 10.1016/ S0945-053X(01)00154-8.

15. Soi $S$, Vinayak $V$, et al. Fluorides and their role in demineralisation and remineralisation. J Dent Sci Oral Rehabil 2013 July-Sep;19-21.

16. Duckworth RM. Pharmacokinetics in the oral cavity: fluoride and other active ingredients; in van Loveren C: toothpastes. Monogr Oral Sci 2013;23:121-135.

17. Fowler $\mathrm{C}$, Wilson $\mathrm{R}$, et al. In vitro microhardness studies on a new anti-erosion desensitizing toothpaste. J Clin Dent 2006;17:100-105.

18. Pradubboon SS, Hamba $\mathrm{H}$, et al. Sodium fluoride mouthrinse used twice daily increased incipient caries lesion remineralisation in an otu model. J Dent March 2014;42(3):271-278. DOI: 10.1016/ j.jdent.2013.12.012.

19. Mehta A, Paramshivam G, et al. Effect of light-curable fluoride varnish on enamel demineralisation adjacent to orthodontic brackets: an in vivo study. Am J Orthod Dentofacial Orthop 2015;148(5):814-820. DOI: 10.1016/j.ajodo.2015.05.022.

20. LiX. The remineralisation of enamel: a review of the literature. J Dent 2014;42:S12-S20. DOI: 10.1016/S0300-5712(14)50003-6.

21. Walsh LJ. Contemporary technologies for remineralisation therapies: a review. Int Dent 2009;11(6):6-16.

22. Kalra DD, Kalra RD, et al. Non fluoride remineralisation: an evidencebased review of contemporary technologies. J Dent Allied Sci 2014;3(1):24-33.

23. Bennett $\mathrm{T}$, van $\mathrm{AC}$, et al. Fluorides and non-fluoride remineralisation systems. Monogr Oral Sci 2013;23:15-26. DOI: 10.1159/000350458.

24. Skrtic D, Antonucci JM, et al. Effect of the monomer and filler system on the remineralising potential of bioactive dental composites based on amorphous calcium phosphate. Polym Adv Technol 2001;12: 369-379.

25. Prestes L, Souza BM, et al. In situ effect of chewing gum containing CPP-ACP on the mineral precipitation of eroded bovine enamel: a surface hardness analysis. J Denti 2013;41(8):747-751. DOI: 10.1016/ j.jdent.2013.06.006.

26. Oliveira P, Fonseca A, et al. Remineralising potential of CPP-ACP creams with and without fluoride in artificial enamel lesions. Aust Dent J 2016;61:45-52. DOI: 10.1111/adj.12305.

27. Mony B, Ebenezar ABR, et al. Effect of chicken egg shell powder solution on early enamel carious lesions: an in vitro preliminary study. J Clin Diagn Res 2015;9(3):ZC30-ZC32. DOI: 10.7860/ JCDR/2015/11404.5656.

28. Sargod SS, Bhat SS, et al. Remineralisation potential using calcium sucrose phosphate (enafix) on artificial carious lesion-a polaroid microscopic study. Ind J Appl Res 2015;5(1):421-423.

29. Julian RJ. Review of bioactive glass: from Hench to hybrids. Acta Biomater 2013;9:4457-4486. DOI: 10.1016/j.actbio.2012.08.023.

30. Andersson $\mathrm{OH}$, Kangasniemi I. Calcium phosphate formation at the surface of bioactive glass in vitro. J Biomed Mater Res 1991;25:1019-1030.

31. Earl JS, Leary RK, et al. Physical and chemical characterization of dentin surface, following treatment with NovaMin technology. J Clin Dent 2011;22:2-67.

32. Hench LL, West JK. Biological applications of bioactive glasses. Life Chem Rep 1996;13:187-241.

33. Chole $D$, Jadhav $Y$, et al. Remineralising agents: minimal invasive therapy a review. J Dent Med Sci 2016;15(2):64-68. DOI: 10.9790/0853150786472.

34. Dong Z, Zhou C. Particle size of $45 S 5$ bioactive glass affected the enamel remineralisation. Mater Sci forum 2014;815:396-400. DOI: 10.4028/www.scientific.net/MSF.815.396.

35. Greenspan DC. NovaMin ${ }^{\oplus}$ and tooth sensitivity—an overview. J Clin Dent 2010;21:61-65.

36. Amin $M$, Mehta $R$, et al. Evaluation of the efficacy of commercially available nano-hydroxyapatite paste as a desensitising agent. Adv Oral Biol 2015;5(1):34-38.

37. Amaechi BT, Mathews SM, et al. Effect of theobromine containing tooth paste on dentin tubule occlusion in situ. Clin Oral Invest 2015;19(1):109-116. DOI: 10.1007/s00784-014-1226-1. 
38. Sheng $X-Y$, Gong $W-Y$, et al. Mineral formation on dentin induced by nano-bioactive glass. CCL 2016;27(9):1509-1514.

39. Makinen K. Sugaralcohols. Caries incidence and remineralisation of caries lesions, a literature review. Int J Dent 2010; 981072.

40. Milburn $\mathrm{JL}$, Henrichs $\mathrm{LE}$, et al. Substantive fluoride release from a new fluoride varnish containing CXP ${ }^{\text {TM }}$. Dentistry 2015;5(12):1-6. DOI: 10.4172/2161-1122.1000350.

41. Brown JP, Amaechi BT, et al. Visual scoring of non cavitated caries lesions and clinical trial efficiency, testing xylitol in caries-active adults. Community Dent Oral Epidemiol 2014;42:271-27.DOI: 10.1111/cdoe.12082.

42. Niu L, Zhang W, et al. Biomimetic remineralisation of dentin. Dent Mater 2014;30:77-96.

43. Zhou YZ, Cao Y, et al. Polydopamine-induced tooth remineralisation. ACS Appl Mater Interfaces 2012;4:6901-6910. DOI: 10.1021/am302041b.

44. Benjamin S, Sharma R, et al. Grape seed extract as a potential remineralising agent: a comparative in vitro study. J Contemp Dent Pract 2012;13(4):425-430.

45. Epasinghe D, Yiu C, et al. Synergistic effect of proanthocyanidin and CPP-ACFP on remineralisation of artificial root caries. Aust Dent $J$ 2015;60(4):463-470. DOI: 10.1111/adj.12249.
46. Amaechi BT. Remineralisation therapies for initial caries lesions. Curr Oral Health Rep June 2015;2(2):95-101. DOI: 10.1007/s40496-0150048-9.

47. Wu XT, Mei ML, et al. A direct electric field aided bio mineralisation system for inducing the remineralisation. Materials 2015;8(11): 7889-7899. DOI: 10.3390/ma8115433.

48. Chen L. Biomimetic remineralisation of human enamel in the presence of polyamidoamine dendrimers in vitro. Caries Res 2015;49:282-290. DOI: 10.1159/000375376.

49. Amaechi BT, Porteous N, et al. Remineralisation of artificial enamel lesions by theobromine. Caries Res 2013;47:399-405. DOI: $10.1159 / 000348589$.

50. Syafira G, Permatasari R, et al. Theobromine effects on enamel surface microhardness: in vitro. J Dent Indones 2012;19(2):32-36.

51. Nasution A, Zawill C. The comparison of enamel hardness between fluoride and theobromine application. Int J Contemp Dent Med Rev 2014; 031214.

52. Cheng $X, X u P$, et al. Arginine promotes fluoride uptake into artificial carious lesions in vitro. Aust Dent J 2015;60(1):104-111. DOI: 10.1111/ adj.12278. 